\title{
Expectations, interactions between agents and technological regimes
}

\author{
CHRISTIAN LE BAS*
}

\begin{abstract}
We argue here two types of interactions within an organization are crucial for understanding how the making of expectations is structured. Our basic assumption is that the making of expectations is realized with different manners in a small firm which works in an entrepreneurial regime than in a large firm of the ologopolistic or routinized regime (see Winter, 1984). We follow the very revelant analysis carried out by Swann and Gilll (1993). In a young small firm with a (very) small number of individuals, in other words when the complexity is weak, the exchange of information among the members is easier than in the case of a larger firm. On the other hand, the process of decision-making is more rapid. The expectations will be flexible. And conversely for the large firms of a routinized regime, because the making expectations is based on (organizational) routines which are the mean to cope with the stronger complexity due to the large number of individual agents. The process of expectations revision will be longer and expectations more difficult to modify. The existence of two different schemes, with regards to the making of expectations, entails some consequences on the stability of growth for each of both technological regimes. We will show the technological regimes have different properties in terms of stability of growth trajectory. The way by which the expectations are made explains these differences.
\end{abstract}

Classification Codes: L2, O0, A1.

\section{Expectations and interactions between economic agents: a general framework}

Economics shares with other sciences the idea the interactions between agents produce effects and new structures. Mainstream thought, founded on general equilibrium analysis, identifies only the interactions built on the relationships in competitive markets. Interactions outside of the market, externalities, may be dealt with by the establishment of property rights. Other approaches focus mainly on the interactions outside of the market for explaining the dynamic properties of evolution. For instance, in the epidemic

\footnotetext{
* Centre Walras, Université Lyon-2, Faculté de Sciences Économiques, 16 Quai Cl. Bernard, 69365 Lyon 07, France. E-mail: lebas@univ-lyon2.fr

Keywords: Interaction, expectations, technical progress, economic agent.
} 
model of diffusion of innovations through contacts between agents, information about the technologies is exchanged and the economy leaves a path with an old technology in order to attain a new path with another technology (Mansfield, 1961). We need a clear definition of the process of interaction. We retain in this paper that given by Manski (2000): Economic agents interact through their actions. The action carried out by an agent affects necessarily the process of decision-making of another agent. It means interaction affects the three dimensions of behavior: constraints, expectations and preferences. For instance, in the general equilibrium approach the agent has a utility function (preferences), expectations about the distribution of subjective probability, and making choices among a set of solutions and constraints. The main point we want to emphasize here is: Expectations are necessarily at the core of the system of interactions between agents ${ }^{1}$.

The second point which needs to be clarified concerns the economic agent who makes his behavior and expectations. Three possibilities exist:

$-\mathrm{He}$ is an individual agent. In such a case we find again the standard general equilibrium framework or the entrepreneurial model from industrial organization (Casson, 1982; Jovanovic, 1982; Kirman, 1992);

- The agent is a team as in Marschak and Radner (1972);

- The agent is a firm (or an "organization" or an "institution"). There are several approaches in competition for understanding the firm behavior (agency relation, coalition, evolutionary economics...). In general, the difference between the oligopolistic (multiproduct) firm and the small firm new in the industry is noted. It is clearly at the foundation of technological environments or regimes described for the first time by Winter $(1984)$. Winter $(1984 ; 1986)$ defines two polar types of regimes: the oligopolistic or routinized regime in which both the (small) number and the ranking of large firms are stable, and the entrepreneurial regime composed of small (new in general) firms in which turbulence (entry/exit) is high.

Complexity constitutes the third and final problem. The basic assumption we make here is that it can be measured by the number of agents in interaction. The agents must be different in the sense they have different characteristics in terms of capacity (competence, knowledge), vision, economic revenue... For instance, it has been shown the development of an agent's idea does not depend on the other ideas that he may have but requires that he meets other agents with (different) ideas (Jovanovic and Rob, 1989).

We argue that it is important to distinguish, on the one hand, the interactions between individual agents within an organization and on the other, the interactions between organizations (firms). In other words, we make a distinction in the same way as it is done in the dynamic theory of populations, the interactions between individuals within a specific population and the interactions between different populations. Table1 summarizes the four main configurations stemming from the crossing of the mode of interactions between individual agents within an organization and the mode of interaction between organizations. It indicates some economic analyses which deal with each case.

\footnotetext{
${ }^{1}$ The archetype is the very simple model of a game with 2 players in which each of them can anticipate the reaction of the other.
} 
Table 1. Individual interactions within organization versus interactions between organizations.

\begin{tabular}{|l|l|l|}
\hline $\begin{array}{l}\text { Interaction inter-organization } \Rightarrow \\
\text { Interaction intra-organization } \Downarrow\end{array}$ & $\begin{array}{l}\text { Small of number of organizations } \\
\text { (limit case: } 2 \text { agents) }\end{array}$ & $\begin{array}{l}\text { Larger number } \\
\text { of organizations }\end{array}$ \\
\hline Small number of individual agents & Limit case: Theory of games & Entrepreunial regime \\
\hline Large number of individual agents & $\begin{array}{l}\text { - Routinized technological regime } \\
\text { - Limit case: Theory of duopole }\end{array}$ & $\begin{array}{l}\text { - Replicators dynamic } \\
\text { - Monopolistic competition }\end{array}$ \\
\hline
\end{tabular}

We argue here these two types of interactions interact and this is crucial for understanding how the making of expectations is structured. Our basic assumption is that the making of expectations happens in a different manner in a small firm from an entrepreneurial regime than in a large firm with an oligopolistic or routinized regime. We follow here the very relevant analysis carried out by Swann and Gill (1993). In a young small firm with a (very) small number of individuals, in other words when the complexity is weak, the exchange of information or knowledge among the members is easy or easier than in the case of larger firm. The process of decision-making is quicker and expectations are flexible. Moreover, acting quickly is a question of survival in a turbulent environment (competitive pressures are very often strong). Conversely for large firms of a routinized regime, the making of expectations is based on (organizational) routines which are meant to cope with the greater complexity due to the large number of individual agents or departments. The process of revising expectations will be longer and expectations are more difficult to modify. Moreover, the stability of the number and the ranking of innovative firms lead to careful behavior. Finally, our approach focuses on knowledge interactions and the formation of organizational expectations follows that of Nonaka's (1995) study on the organizational creation processes and that of Evans (2000) when it suggest 2 kinds of learning processes (educative and adaptative) in the context of rational expectations. The existence of 2 different schemes with regards the making of expectations has some consequences on the stability of growth for each of the 2 technological regimes. We will show how the technological regimes have different properties in terms of the stability of their growth trajectory. The way by which expectations are formed explains these differences.

The basic assumptions of our own approach are:

- The economy works on the basis of evolutionary mechanisms (those described in Nelson and Winter, 1982; Winter, 1984, 1986; Metcalfe and Gibbons, 1986);

- We particularly focus our attention on the making of expectations regarding technical progress, these are adaptative ${ }^{2}$;

- Agents are in a situation of "contextual interactions" 3 .

\footnotetext{
${ }^{2}$ It seems to us there are three important intellectual roots of the contemporary evolutionary view of technology expectations: the notion of "image" put forward by Penrose (1959), the implications drawn by Rosenberg (1976) from the analysis of technological expectations, the definition of economic competence suggested by the Evolutionary Swedish School (Carlsson and Eliasson, 1994).

${ }^{3}$ This means that "the propensity of a person to behave in some way vary with exogeneous characteristics of the group members" (Manski, 2000, p. 23).
} 
The paper is built as follows. In Section 2 we define expectation as a coordinating capacity and identify some implications of this definition. In Section 3, the two different schemes of the making of expectations are defined in the context of the kinds of interaction. The links between expectations and stability of growth process are at the core of the last section.

\section{The capacity to expect as a coordinating capacity: implications and analysis of tensions}

The capacity to expect or the capacity to form expectations concerning future events is a special kind of capacity. In general terms, it is a coordinating capacity $y_{2}$ capacity aiming to coordinate the firm's activity over time. More precisely, it means the coordination of the conditions of to-morrow with the action that the firm has to undertake today in order to adapt its behaviors and its structures inherited from yesterday. So, the path followed by the firm is as much a matter of visions (expectations) as a matter of corporate histories. All the characteristics of capability can be applied to the capacity to expect. As capability is know-how, manifested in action, and accumulated rather than the product of logical analysis (Loasby, 1999), capacity to expect is a special kind of learning. So only adaptative expectations are conceivable in our framework. Rational expectations (the best product of logical economic analysis) are consequently totally irrelevant (see Manski, 2000 for proofs ${ }^{4}$ ). As capability is both individual and collective, capability to expect concerns each member of an organization and the organization as a whole. As Loasby (1999) claimed, knowing how to appear the expectations of other member of an organization is a very important skill for anyone who whishes to become an effective organization member. Similarly, Aoki (1988) has shown how the Japanese firms foster the expectations of workers at lowers levels in order to solve certain (small) problems and to absorb shocks (Swann and Gill, 1993).

One important consequence of considering expectations as a coordinating capacity is that we take into account not just corporate history but also the corporate vision of the future. The process of expectation is a part of corporate learning processes. This type of capacity is accumulated in the same way as any other form of capacity by the general laws regarding the cumulative nature of learning. The competences tend to change very slowly (capacity evolves gradually within the production processes or within the firm). The firm provides elements of institutional continuity over time in its functions as a repository of specific competences (Cantwell and Fai, 1999). Despite this incremental and path dependent character of learning (in brief the fact that history matters), the capability to expect can not be built without a certain vision of the future. Learning needs initiative and imagination. As Loasby (1999) pointed out, capabilities are in large

\footnotetext{
${ }^{4}$ We suppose here the debate between (old) Monetarism (adaptative expectations) and the NEC (rational expectations) known.
} 
measure a by-product of activities, but what matters at any point of time is the range of future activities which they make possible. What gives its salience is the possibility of shaping capabilities, and especially of configuring clusters of capabilities, in an attempt to make some preparations for future events, which, though not predictable can be imagined (Loasby, 1999).

It is clear at this stage that there is a trade-off in the accumulation of the capacity to expect between corporate history and vision. For this reason, as we will see, adaptative expectations are the best way of making of expectations. The important point with such a kind of expectations is the sharing between backward-looking (history) and forwardlooking (vision) depends on the idiosyncrastic nature of the firm. In regards to the position of the firm on trade-off some general patterns can be drawn:

1. Sectoral specificities matter. An emerging new sector has no history strictly-speaking, each firm has its own vision of products, markets, technologies. In their expectations, the forward-looking aspect will be determinant. We may expect that the reverse will be true for a mature sector.

2. As technological trajectories are now concerned, assumptions could be made: for instance, in the case of a "science-based trajectory", the exercises of technological and scientific foresights are without doubt more important than for a "supplier-dominated trajectory" in which previous linkages between suppliers and customers are probably more determinant. But these very first remarks need to be still verified.

3. The size of a firm also accounts for understanding the position of the firm on the tradeoff. For instance, small firm revises strongly and very often the last expectations whereas large firms do it more incrementally, due to the inertia in their process of decision-making (Swann and Gill, 1993). Along these lines of thoughts, Witt (1998) has recently emphasizes the crucial economic role of entrepreneurial vision. If the creation of a firm always leads to some entrepreneurial imaginings about the business to be done, the problem is more complicated with respect to the firm recently established. A dilemma has to be analyzed: “... an extremely important entrepreneurial activity is the attempt to shape the firm member's perceptions of means and ends in such a way that entrepreneurial business conception becomes collectively shared interpretation patterns. On one hand, there is a notion that firm members should be encouraged to engage in creative problem-solving and be innovative. For an enterprise to prosper and grow, it is indeed important for entrepreneurial vision to be translated into day-to-day problem-solving by the members of the firm in their own specific domain. As it was noted long ago, a tight minoriting regime is incompatible with such behavior. On the other hand, in the absence of control, it appears uncertain whether employees do indeed comply with their entrepreneurial conception, or whether they pursue their separate interests at the expense of the firm" (Witt, 1998). In many cases, such a dilemma is solved by "managerial methods". 
There is another trade-off to be found out in organizational learning, the trade-off between exploitation and exploration ${ }^{5}$. In fact, there is a tension between:

- Exploitation of the available knowledge that involves refinement of available technology; this process is oriented towards the search for higher efficiency without too much risks.

- Exploration of new technological possibilities, search for novelty with risky investment in knowledge.

Taking into account this trade-off offers a very (new) rich perspective with respect to the process of expectations making. The process of expectations formation contains, on one hand a part associated with the exploitation of knowledge necessary for building the firm's vision, and on the other hand, a part associated with the exploration of future business or technological opportunities. How this tension is solved, that is to say in what proportions exploitation and exploration are combined and eventually balanced, is not precisely a dilemma. For instance, March (1990) has stressed the importance of the social context of the firm in which learning takes place. A distinctive feature of this context is "the mutual learning of an organization and the individuals in it. Organizations store knowledge in their procedures, norms, rules, and forms. They accumulate such knowledge over time, learning from their members. At the same time, individuals in an organization are socialized to organisational beliefs". On this basis, it is clear that, as Dosi and Marengo (1992) pointed out, "high degree of differentiation of knowledge among the members of an organisation increases the total amount of knowledge possessed by the organisation. But differentiation makes coordination more difficult and ultimately can inhibit the social exploitation of this knowledge basis. On the contrary, a widely held body of organizational knowledge facilitates coordination and specialization, but reduces the scope for decentralized experimentation". In our framework we are able to tell the same story by putting interaction at the core of the analysis; interactions are probably less efficient when differentiation is higher and vice vers $a^{6}$. It seems to us that in the case of adaptative expectations, exploitation means giving a greater importance to the expectations formed in the past, and finally making a weak revision of these past expectations. Conversely, when exploration is greater than exploitation, it means giving a lower weight to expectations made in the past, and taking more strongly into account the information collected on the present state of the environment. So we will make the assumption that a large firm exploits more, whereas a small firm explores more.

\section{Intra-organization interactions, inter-organizations interactions and the making of expectations}

The latter observations will help us to pursue our study by putting explicitly the two figures of interactions we have defined (interactions within organization, interactions

\footnotetext{
5 To some extent this trade-off is close to the previous (backward or forward looking).

${ }^{6}$ But this strongly interacts with another tension, the tension between centralization and decentralization.
} 
between organizations) at the heart of the analysis. We follow here the very relevant remarks made by Swann and Gill (1993) based on evidence. Two polar cases can be distinguished. In a young small firm with a small number of individuals, in other words when complexity is weak, the exchange of information among the members is easy or easier than in the case of larger firms. On the other hand, the process of decision-making is more rapid. To some extent, there is no real inertia (in the case limit in which there is only one individual - the entrepreneur - the process of decision making is totally governed by this only individual). In this case the firm is very specialized, it can consequently gather the available relevant information, and expectations are flexible. They correspond to the case where "exploration" is greater than "exploitation". In terms of the revision of expectations, this means that the decision-maker will give more importance to the information stemming from the present state and less importance to the oldest information (associated to remote times). In a word, expectations are generally quickly modified. The case is typical of the industrial environment termed by Winter (1984) as "entrepreneurial regime". In the second (polar) case, termed by Winter (1984) as a routinized regime ${ }^{7}$, there are only a small number of (very) large firms encompassing many divisions or departments. The decision-process is longer due to the necessary interactions and exchanges between individuals, departments and plants. Inertia is stronger. "Exploitation" is more important than "exploration". History matters more. The firm is less reactive. So in the case of multidivisional firm which characterizes the routinized regime, expectations change very slowly.

Let now suppose a very general formula for expectations making (this definition is standard in the literature. For more details concerning notations and definition see: Le Bas, 1997):

$$
x^{\mathrm{e}}(t)=\varphi x(t-1)+(1-\varphi) x^{\mathrm{e}}(t-1) \text { with } 0<\varphi<1
$$

where $x^{\mathrm{e}}(t)$ is the expected value of the variable $x$ at time $t$ and $x(t-1)$ is the real true value of the variable $x$ at time $t-1$ observed by the firm. For $\varphi=0$, the firm does not modify its expectations, it maintains the same value. For $\varphi=1$, expectations are naïve, the firm takes the last observed value for the expected value. Our main assumption is $\varphi$ is high in an entrepreneurial regime and low in a routinized regime.

\section{Technological regimes, making of expectations and stability of growth process}

We now want to assess the consequences of these two ways of making expectations on the dynamics of the economy. We suppose here that in each regime the firms build their expectations in the same manner. In a word, the paramater $\varphi$ will have the same value for all the firms. In a sense, we suppose that regarding expectations making firms are homogeneous. We know for instance that interactions between firms push them to choose to imitate other firms for many reasons (see Manski, 2000; Orléan, 1998). So it is not a

\footnotetext{
${ }^{7}$ In fact, Winter envisaged two variants with entry of new small firms and without entry. The latter case is here the only retained.
} 
"heroic assumption", it simplifies the demonstration without creating to many problems. We suggest a very simple growth-model along Kaldor-Rosenberg lines ${ }^{8}$. We suppose the firms in the economy make their choice concerning investment in equipment with the same manner. Following the remarks made by Rosenberg (1976), we consider the rate of investment $I(t)$ (the investment by unit of gross product) made in the period $t$ depends crucially on the expected rate of technical progress ${ }^{9}\left(M^{\mathrm{e}}(t)\right)$ the growth rate of productivity. So we suppose all technical progress is equipment-embodied. The decision to invest means in fact that it is also a decision to improve the methods of production (innovation is bought from the supplier of equipment). The other factors which determine the decision to invest such as demand conditions and competition, are pooled in the parameter $b$. The relation between the variables has the following linear form:

$$
I(t)=a\left(M^{\mathrm{e}}(t)\right)+b \quad \text { with }(a \leq 0 .)
$$

This means that when the expected rate of technical progress is high, the investment made will be less important (an idea from Rosenberg, 1976). The two variables $I(t)$ and $M^{\mathfrak{e}}(t)$ are pure numbers (without units). We have another relationship linking the real rate of technical progress to the rate of investment made in the period. But this relationship is not contemporaneous, there is a lag of one time period. This relationship wellknown in the Kaldorian growth tradition can be written:

$$
M(t)=\alpha I(t-1)+\beta \quad \alpha \geq 0
$$

where $\beta$ is the autonomous rate of technical progress.

When we combine (1) and (2), we have:

$$
M(t)=\alpha a\left(M^{\mathrm{e}}(t-1)\right)+(\alpha b+\beta) .
$$

In a word, this is the expected rate of technical change for tomorrow which determines the realized rate of technical change (to day). So we have an illustration of the thesis that beliefs entail effects. The model would not be complete without an equation which describes how the making of expectations works. We argued that "adaptative expectations" is the only way of thinking of how firms build their expectations. In this way, we take into account their vision of the future and their learning (from the past). So we will have:

$$
M^{\mathrm{e}}(t)=\varphi M(t-1)+(1-\varphi) M^{\mathrm{e}}(t-1)
$$

where $\varphi$ indicates the revision parameter.

From (3) and (4), we write:

$$
M^{\mathrm{e}}(t)=(1-\varphi) M^{\mathrm{e}}(t-1)+\varphi \alpha a M^{\mathrm{e}}(t-2)+(\alpha b+\beta) .
$$

The equation of recurrence has only one semi-stationary solution:

$$
M^{\mathrm{e}}=(\alpha b+\beta) /(1-\alpha a) \text {. }
$$

\footnotetext{
${ }^{8}$ For more details see Le Bas (1997).

9 That is to say on "technological expectations".
} 
This unique solution is always positive. This gives the equilibrium rate of technical progress $M=M^{\mathrm{e}}$. It does not depend on $\varphi$, the parameter which describes the law of expectations making. We mainly are interested by the conditions of stability of the unique equilibrium solution. We have shown elsewhere (Le Bas, 1997) this solution is always stable but there are two ways of converging. For high values of $\varphi$ (entrepreneurial regime) the trajectory of our economy converges towards the fix-point with fluctuations (excepted for the cases where $a$ and $\alpha$ are weak), for low values of $\varphi$ (routinized regime) the economy converges monotonously toward the equilibrium. So the conditions of stability are very different, each technological regime expresses its own-path toward equilibrium. This finally means the routinized regime is more stable than the entrepreneurial one, this property is due to the expectations making ${ }^{10}$.

\section{Conclusion}

The basic idea of the paper is that the way in which individuals interact within an economic organization (a firm) explains the making of the expectations of the organization. Moreover, the way in which organizations interact together in their environment tend to define the technological regime (Winter, 1984; 1986): routinized regime versus entrepreneurial regime. The findings depend crucially on the way in which firms form their expectations. We considered the technological expectations formed by industrial firms at the industry level. We follow the seminal remarks done by Swann and Gill (1993) on the two ways of making adaptative expectations: in a small firm with a small number of individuals (when the complexity is weak) the exchange of information among the members is easier than in the case of larger firm. Expectations will be flexible. Conversely, in the large firms of the routinized regime in which the making expectations is based on (organizational) routines, greater the complexity due to the large number of individual agents or departments will be and the process of revising expectations will be longer and expectations more difficult to modify. The existence of two different schemes of the making of expectations has some consequences on the stability of growth for each of the two technological regimes identified in the evolutionary analysis. The reduced form of a KaldorRosenberg growth-model suggests a unique stable equilibrium growth path. The study of the stability conditions allows us to stress that there is a difference between the two regimes. In a routinized regime the convergence path toward the fix point is monotonous, it is characterized by fluctuations in an entrepreneurial regime. These findings depend crucially on the way by which firms make or revise their expectations.

Acknowledgements. This paper was mainly written during my stay as a Fellow at Brown University (RI, USA) in June-July 2000. I would particularly like to thank the department of foreign studies for its support.

\footnotetext{
${ }^{10}$ Bresche et al. (2000) gives statistical evidence which supports our findings. In particular the entrepreneurial regime (characterized by low concentration of innovative activities and high relevance of new innovators) has a low stability in the ranking of innovators. This differs from the routinized regime.
} 


\section{References}

Aoki M. (1988) Information, incentives and bargaining in the Japanese economy. Cambridge University Press, New York.

Bresche S., Malherba F., Orsenigo L. (2000) Technological regimes and Schumpeterian patterns of innovations, The Economic Journal, 463, pp. 388-410.

Cantwell J., Fai F. (1999) Firms of the source of innovation and growth: the evolution of technological competence, Journal of Evolutionary Economics, 9 (3), pp. 331-366.

Carlsson B., Eliasson G. (1994) The nature and importance of economic competence, Industrial and Corporate Change, 3, pp. 687-711.

Casson M. (1982) The Entrepreneur. Blackwell, Oxford. Traduction française : L'Entrepreneur. Economica, Paris, 1991.

Dosi G., Marengo L. (1992) Some elements of an evolutionary theory of organizational competences. In: Tenth World Congress of the International Economic Association, August, Moscow.

Evans G. (2000) Expectations in macroeconomics: Adaptive versus educative learning. In: Colloque de l'Association française de Sciences Économiques.

Jovanovic B. (1982) Selection and evolution of industry, Econometrica, 50 (2), pp. 649-670.

Jovanovic B., Rob R. (1989) The growth and diffusion of knowledge, Review of Economic Studies, 56, pp. 569-582.

Kirman A. (1992) Variety: The coexistence of techniques, Revue d'Économie Industrielle, $\mathrm{n}^{\circ} 59$, pp. 62-74.

Le Bas C. (1997) Anticipations, compétence économique et régimes technologiques, Économie Appliquée, $\mathrm{n}^{\circ}$ 2, pp. 37-61.

Loasby B.J. (1999) Comment Edith T. Penrose se place dans la filiation des idées économiques, Économies et Sociétés, Série Oeconomia, pp. 103-121.

Mansfield E. (1961) Technical change and the rate of imitation, Econometrica, pp. 741-66.

Manski F. (2000) Economic analysis of social interactions. NBER Working Paper No. 7580, March.

March J. (1990) Exploration and exploitation in organizational learning. Mimeo, Stanford University.

Marschak J., Radner R. (1972) Economic theory of teams. Yale University Press, New Haven.

Metcalfe S., Gibbons M. (1986) Technological variety and the process of competition, Économie Appliquée, No. 3, pp . 493-520.

Nelson R., Winter S.G. (1982) An evolutionnary theory economic of change. Harvard University Press, Cambridge, MA.

Nonaka I. (1995) Managing innovation as an organizational knowledge creation process. In: Allouch J., Pogorel G. (Eds.), Technology managment and corporate strategies: A tricontinental perspective, Elsevier Science B.V., Amsterdam, pp. 73-109.

Orléan A. (1998) Informational Influence and the Ambivalence of Imitation. In: Lesourne J., Orlean A. (Eds.), Advances in Self-Organisation and Evolutionnary Economics. Economica, Paris.

Penrose E. (1959) The theory of the growth of the firm. Blackwell, Oxford.

Rosenberg N. (1976) On technological expectations, Economic Journal, pp. 523-535.

Schackle G.L. (1961) Decision, order and time in human affairs. Cambridge University Press, Cambridge. 
Swann P., Gill J. (1993) Corporate vision and rapid technological change. Routledge, London. Winter S.G. (1984) Schumpeterian competition in alternative technological regimes, Journal of Economic Behaviour and Organisation, 5, pp. 287-320.

Winter S.G. (1986) Schumpeterian competition in technological regimes. In: Day R.H., Eliasson G. (Eds.), The Dynamics of Market Economics. North-Holland, Amsterdam.

Witt U. (1998) Imagination and leadership: The neglected dimension of an evolutionary theory of the firm, Journal of Economic Behaviour and Organization, 35, pp. 161-178.

To access this journal online: www.edpsciences.org 